\title{
Stopping the Arms Race in Space
}

Kenneth A. Johnson

Jniversity of Michigan 'ntroduction: The threat from new veapon systems

Jn 26 May 1972 the US and the USSR signed he Anti-Ballistic-Missile (ABM) Treaty conluding what many experts consider to have Jeen the most significant arms control agreenent to date. The ABM Treaty and the 1974 ?rotocol arrested a rapidly expanding and exJensive defensive arms race by limiting 100 $\mathrm{ABMs}$ to one site, and banning their improvenent or the development of new systems. This agreement stabilized the arms competition beween the superpowers in a number of other ways. By ensuring the vulnerability of each ration's defenses and cities to their enemy's etaliatory forces, the ABM ban prevented a enewed offensive missile race and was the srucial factor in the agreement to place a ceiling on offensive weapons in the SALT I and II accords. The current hope for substantial arms reductions has been made possible by an absence of defensive weapons.

In the ten years since the signing of this historic agreement there have been some new developments which threaten not only future arms control agreements, but also the likelihood of peace. One serious problem is that the US and USSR are both rapidly developing and deploying anti-satellite weapons (ASATs). Even more dangerous than the ASAT competition is the US and Soviet work on space-based laser and particle-beam ABM systems. If both nations continue to develop these weapons they will greatly increase the possibility of war, promote instead of reduce the propensity to build additional offensive weapons, and waste billions of dollars. With the worldwide interest in arms control and weapons reduction, and the restarting of arms control negotiations by the US and USSR, there exists an opportunity to ban ASAT weapons and energy-beam ABM systems.

\section{Description of ASATs and advanced ABM systems}

Anti-satellite weapons are designed to destroy enemy intelligence, early warning, or communications satellites. There are currently four basic ASAT systems: orbiting 'satellite bombs', orbiting anti-satellite missiles, groundbased ASAT missiles and energy-beam weapons. The USSR was the first to test an ASAT weapon. In 1977 the Soviets launched a satellite that could be maneuvered close to a target satellite and then detonated, destroying the target by schrapnel. The Soviets have since tested more advanced versions of this 'satellite bomb' and are also thought to be getting ready a satellite that will be able to launch missiles at several target satellites. The US has developed a ground-based ASAT missile that will be fired from an F-15 fighter. The F-15 will fly high into the atmosphere where a 2-stage booster rocket will be fired. The missile will then home to the target satellite, destroying it upon impact. Both nations are also working on space-based beam weapons that would be able to destroy a satellite from a considerable distance (discussed in greater detail below).

In addition to developing ASAT capabilities, the superpowers are also developing ASAT 
counter-measures to enhance the survivability of satellites. Some of these measures include: the hardening of satellites to make them more difficult to destroy by fragments and energybeams; the duplication of vital systems so the satellite might remain operational even if one system is damaged; maneuverability enhancement that will allow a satellite to move away from an approaching satellite or missile; the development of ASAT missiles for self-defense; and the deployment of a number of identical satellites to ensure that some will survive ASAT attacks.

\section{Beam weapons}

Lasers and particle-beams have many possible ASAT, counter ASAT, and ABM uses. These energy-beams have many properties that would make them a desirable weapon. The beams have the potential to be very accurate and will destroy (or damage) their target on contact. What some defense planners foresee is an energy beam that will travel at the speed of light over hundreds of kilometers and destroy or damage a strategic missile or satellite by concentrating a large amount of energy on a small area (similar to what is seen in science fiction movies). In theory, a laser weapon in orbit about $1000 \mathrm{~km}$ above the earth can destroy strategic missiles in the boost stage. ${ }^{1}$

\section{Why ASAT and energy beam ABM systems are dangerous}

The ASAT and advanced ABM weapons should be banned for a number of reasons. First, these weapons are inherently destabilizing; in other words, in a crisis situation their existence would tend to make war more likely to occur. Since both nations depend heavily on satellites to warn them of an enemy attack, monitor military movements, and to communicate with their strategic and conventional forces, the loss of these satellites could blind them and prevent retaliation. Since both the US and USSR possess the capability to destroy each other's land-based strategic forces, the nation that attacks first, theoretically, can gain an important advantage in damage limitation and is in a better position to negotiate an end to the war. The feared or actual destruction of a nation's early warning, intelligence, and command-control and communications $\left(\mathrm{C}^{3}\right)$ satellites in a crisis could cause its leaders to order an escalation of the level of military activity (which could trigger an escalatory cycle ending in war), or it could convince these leaders that war was imminent and cause them to launch a preemptive strike. Second, future arms control agreements will depend on intelligence satellites to verify compliance with the agreement. The possibility that a nation's verification capability will be disrupted might make the superpowers more reluctant to reach arms control agreements.

In theory, the existence of an ABM system will reduce the damage an enemy can inflict. A system capable of defending an entire nation, such as an energy beam system, will make land-based ICBMs and other strategic forces less vulnerable to a counterforce strike, and will limit the retaliatory damage inflicted on cities. In a crisis, a nation's leaders fearing the loss of their ICBMs, $\mathrm{C}^{3}$, and other strategic forces to an enemy counterforce strike and questioning their ability to retaliate, might decide to preempt hoping that their own ABM system would limit damage enough to make the war 'winnable'. In addition to making war more likely, the deployment of ABM systems would rule out any further strategic arms control agreements. If the US and USSR cannot be certain they will be able to inflict intolerable damage on their enemy, they will not agree to limit arms. Instead, the deployment of advanced ABM systems would stimulate an offensive and defensive arms race.

\section{Effectiveness and expense}

One of the factors that contributed to the ban of current ABM systems was their questionable effectiveness in destroying enemy missiles. It was far easier and much cheaper to produce additional offensive missiles and effective countermeasures against any ABM system, than it was to deploy the ABM system. Some 
experts are again convinced that the same principles would hold for the energy beam systems. There are many large technical and physical problems a satellite based energybeam system would face. The physics of laser and particle-beam propagation over large distances make it questionable whether these beams would be strong or accurate enough to perform their mission ${ }^{2}$. Since these very expensive satellites would not be in a geosynchronous orbit, because it would put them out of their projected range, a large number would be necessary to protect a nation from attack. Furthermore, each satellite would have to be capable of tracking and destroying more than 1000 missiles during an eight minute boost period. This capability is not projected until the late 1990 s or 21 st century.

Even if such a system were feasible, there are many counter-measures that could protect the missiles; reflective surfaces, abative coatings, and other materials that could withstand the beam's energy could be cheaply used.

Highly maneuverable missiles, stealthy coatings and designs to limit tracking ability, chaff, and other jamming measures could be used to blind the satellite's tracking system. The energy beam ABM weapons would also be ineffective against depressed trajectory missiles, cruise missiles, and bombers. The deployment of satellite based ABM systems would also make ASAT weapons a certainty. Thus, an ABM system would have to be capable of defending itself from attack.

The expense of the ASAT and beam ABM systems would be staggering. Despite the fact that energy beam systems are 15 years off, the Reagan Administration budgeted approximately 350 million for research in 1982 and 500 million in 1983. While much of the research on high energy beams has possible industrial and scientific application (such as fusion), much of these expenditures will be wasted. The US ASAT program, for instance, will cost approximately 1.5 billion dollars for research, development, and initial deployment.

\section{Legal questions}

The deployment of the ASAT and energy beam ABM systems also raises a number of legal questions. The Outer Space Treaty of 1967, while banning the placement of nuclear weapons in space, does not specifically exclude other military weapons. Nevertheless, ASAT and ABM weapons in space would violate the intent of the Treaty and the historical precedents of space use. A nation is not supposed to interfere with another's missions or property in space; ASAT weapons certainly violate this principle. Another interesting question ASAT deployment raises is how astronauts in the US or Soviet space shuttles would be treated, since a substantial number of these missions deal with military matters. The Treaty maintains that astronauts shall be regarded as envoys of mankind'. Yet, will their military role in deploying or servicing ASATs or ABMs make them fair game for ASATs?

Deployment of ABMs in space may also violate the 1972 ABM accord. As the Treaty now stands, an ABM system is defined to consist of interceptor missiles, launchers, and $A B M$ radars. Yet, "in the event $A B M$ systems based on physical principles and including components capable of being substituted for ABM interceptor missiles, ABM launchers... are created in the future, specific limitations on such systems and their components would be subject to a discussion in accordance with article XIII and XIV of the Treaty'. Continuing, Article $V$ specifically states that each party undertakes not to develop, test or deploy ABM systems or components which are sea-based, air-based or space-based. Furthermore, Chief US Negotiator for the ABM and SALT I accords, Gerald Smith, maintained that the Nixon Administration specifically wanted to ban the deployment of other ABM systems (called futuristics), but the Soviet military balked. Nevertheless, Smith maintained that the principles and intent of the agreement applied to futuristics as well. ${ }^{3}$ 
Verification and accord possibility

The verification of an agreement banning these weapons is well within the capabilities of both nations. Space based ABM and advanced ASAT (ground or space based) will require extensive testing which can be easily observed. Although limited ASAT capability exists on both sides, there is no reason- to believe that this should prevent an agreement. In 1972 both the US and USSR possessed ABM capability and each side was willing to forego further development and testing; there is no reason that this could not be the case with ASATs and energy beam ABMs. There are a number of precedents for banning tested, deployed, and untested weapons. In addition to the ABM Treaty, the Space, the Antarctic, and the Seabed Treaties all have sought, in one form or another, to prevent the introduction of weapons into new areas.

The US and USSR were close to an agreement on banning ASATs in 1979, but the Carter Administration broke off talks when the USSR invaded Afghanistan. Unfortunately, the Reagan Administration has not reopened these talks; apparently Reagan is content to let the military have their way. The Soviets have since called for the ban of ASATs and have introduced resolutions to that effect in the UN. There is no political reason that should prevent these weapons from being banned. Arms control treaties, after all, are articles of hope and faith; it is the desire for a safer and better future that makes them possible. In addition to preventing the waste of billions of dollars and roubles, and reducing dangerous competition between the superpowers, the banning of anti-satellite weapons and energy beam antiballistic missile systems will reduce the chance of war, making a better future possible.

\section{NOTES}

1. For a detailed treatment of the nature of laser and particle beam weapons, see John Parmentola and Kosta Tsipis, 'Particle-Beam Weapons', Scienrific American 240 4. April 1979, pp. 54-65, and Kosta Tsipis, 'Laser Weapons,' Scientific American 2456 December 1981, pp. 51-57.

2. Ibid.

3. Gerald Smith, Doubletalk. New York: Doubleday and Co., 1980, p. 265. 